\title{
Syndecan-1 expression in mammary epithelial tumor cells is E-cadherin-
} \section{dependent}

\author{
Sirpa Leppä1,2,*, Kris Vleminckx ${ }^{3}$, Frans Van Roy ${ }^{3}$ and Markku Jalkanen ${ }^{2}$ \\ ${ }^{1}$ Department of Medical Biochemistry, University of Turku, Kiinamyllynkatu 10, FIN-20520 Turku, Finland \\ 2Turku Centre for Biotechnology, PO Box 123, FIN-20521 Turku, Finland \\ 3 Laboratory of Molecular Biology, University of Ghent, B-9000 Ghent, Belgium \\ ${ }^{*}$ Author for correspondence at address 2
}

\section{SUMMARY}

E-cadherin is a $\mathrm{Ca}^{2+}$-dependent cell-cell adhesion molecule, which is mainly expressed in epithelial cells. Recent studies have shown that E-cadherin has an important role as an invasion suppressor molecule in epithelial tumor cells. Syndecan-1 is a cell surface proteoglycan that has been implicated in a number of cellular functions including cellcell adhesion, cell-matrix anchorage and growth factor presentation for signalling receptors. Its suppression has also been shown to be associated with malignant transformation of epithelial cells. In order to better understand the coordinated regulation of cell-cell and cell-matrix interactions during malignant transformation, we have studied the expression of syndecan-1 in malignant mammary tumor cells genetically manipulated for E-cadherin expression. In invasive NM-e-ras-MAC1 cells, where E-cadherin was partially downregulated by specific antisense RNA, syndecan-1 expression was suppressed. Furthermore, transfection of E-cadherin cDNA into invasive NM-f-rasTD cells resulted in the upregulation of syndecan-1 expression in association with decreased invasiveness. In both cases, regulation of syndecan-1 occurred post-transcriptionally, since syndecan-1 mRNA levels remained unchanged. Instead, a translational regulation is suggested, since syndecan-1 core protein synthesis was E-cadherin dependent. Another cell adhesion protein, $\beta 1$-integrin was not affected by E-cadherin expression. The data provide an example of coordinated changes in the expression of two cell adhesion molecules, syndecan-1 and E-cadherin during epithelial cell transformation.

Key words: Cell adhesion, Malignant transformation, E-Cadherin, Syndecan-1, Invasion

\section{INTRODUCTION}

Invasion of tissues by tumor cells requires that cells dissociate from the initial tumor, adhere to the extracellular matrix of basement membrane, and secrete specific proteolytic enzymes that can degrade the matrix. Eventually, the invasive cells may migrate to distant organs to form metastases (Liotta et al., 1986; Mareel et al., 1991b). The acquisition of an invasive and metastatic phenotype seems to be dependent on activation or suppression of molecules associated with cell adhesion. One example of such molecules is E-cadherin, which is a calcium dependent cell-cell adhesion molecule that mediates homophilic binding between epithelial cells (Takeichi, 1990, 1991, 1993). E-cadherin belongs to a family of more than 20 different members. The classical E-, P-, and N-cadherin represent a subfamily of glycoproteins defined by a common basic structure. They consist of an extracellular domain containing four major repeats, a single transmembrane domain, and a highly conserved cytoplasmic domain. The latter interacts with $\alpha$ and $\beta$ catenins, plakoglobin, and p120, which in turn appear to interact with the cytoskeleton (Nagafuchi and Takeichi, 1989; Ozawa et al., 1989; McCrea et al., 1991;
Reynolds et al., 1994; Shibamoto et al., 1995). Interaction of cadherins with these cytoplasmic proteins is essential for their cell binding function since any defective interactions between these molecules appear to pertub cell-cell adhesion (Nagafuchi and Takeichi, 1988; Ozawa et al., 1989; Oyama et al., 1994; Kawanishi et al., 1995).

It has become increasingly apparent that an impaired function of E-cadherin is associated with the development of the invasive phenotype. In tissue culture conditions reduced expression of E-cadherin has been shown to correlate with the invasive phenotype of cancer cells (Behrens et al., 1989; Frixen et al., 1991; Oda et al., 1994). Furthermore, the invasiveness has been reduced or abrogated by exogeneous expression of $\mathrm{E}$ cadherin in various epithelial tumor cells (Frixen et al., 1991; Vleminckx et al., 1991). Alternatively, down-regulation of Ecadherin expression by specific antisense RNA has been shown to render invasiveness to epithelial tumor cells of mouse mammary gland origin (Vleminckx et al., 1991). In some invasive tumor cells, which still express E-cadherin, an adequate interaction with catenins may be perturbed (Matsuyoshi et al., 1992; Shimoyama et al., 1992; Morton et al., 1993; Kawanishi et al., 1995). The discovery of E-cadherin 
mutations in diffuse gastric carcinomas provides strong in vivo evidence that alterations in E-cadherin play a major role in the development of invasive cancer (Becker et al., 1994; Oda et al., 1994).

The adhesive interactions of the cells with the extracellular matrix are also modified during malignant transformation. The syndecans, which are cell surface heparan and chondroitin sulfate proteoglycans, comprise a family of adhesion molecules that participate in cell-matrix interactions (Bernfield et al., 1992; Elenius and Jalkanen, 1994). They consist of a large distinct ectodomain containing attachment sites for glycosaminoglycans, besides highly conserved transmembrane and cytoplasmic domains. Syndecan-1 is a well characterized member of this protein family. It can selectively bind matrix molecules via its glycosaminoglycan side chains (Koda et al., 1985; Saunders and Bernfield, 1988; Sun et al., 1989; Salmivirta et al., 1991, 1992b, 1994), and simultaneously interact with heparin binding growth factor FGF-2 (Salmivirta et al., 1992a). In spite of a colocalization of syndecan-1 with actin filaments in epithelial cells (Rapraeger et al., 1986), the cytoplasmic domain of syndecan-1 does not directly mediate the interaction with the cytoskeleton (Miettinen and Jalkanen, 1994). However, the cytoplasmic domain is needed for a proper targeting of syndecan-1 onto basolateral surfaces of epithelial cells (Miettinen et al., 1994).

Syndecan-1 expression is suppressed in malignant transformation of mammary epithelial cells induced by steroid (Leppä et al., 1991) or Ha-ras oncogene (Kirjavainen et al., 1993) as well as in chemically transformed keratinocytes (Inki et al., 1992a). Transfection of syndecan-1 cDNA into mouse mammary epithelial tumor cells restores the epithelioid phenotype, and inhibits malignant growth (Leppä et al., 1992; Mali et al., 1994), whereas the loss of syndecan-1 by the expression of antisense RNA causes a fusiform morphology and anchorage-independent growth (Kato et al., 1995). These results suggest that syndecan-1 is required in the stabilization of epithelioid morphology. In addition, expression of syndecan-1 in both epithelioid and B-lymphoid cells inhibits their invasion into type I collagen (Kato et al., 1995; Liebersbach and Sanderson, 1994). In immunohistochemical studies, syndecan-1 suppression has also been associated with malignant phenotype and poor differentiation of mouse skin tumors induced by UV-irradiation (Inki et al., 1991), in carcinomas produced from transformed mouse keratinocytes in nude mice (Inki et al., 1992b) and in human squamous cell carcinomas (Inki et al., 1994a,b,c).

Deregulation of syndecan-1 expression in malignant transformation is still poorly understood. Some tumor cells can post-translationally modify syndecan-1 expression by altering its glycosylation (Inki et al., 1992a). Regulation of syndecan1 expression also appears to involve post-transcriptional suppression (Kirjavainen et al., 1993; Yeaman and Rapraeger, 1993; Sneed et al., 1994), which may provide a notable mechanism to control the expression of this molecule. In this study we have investigated syndecan-1 expression in epithelial tumor cells genetically manipulated by E-cadherin. We show that localization and expression levels of syndecan-1 mimic that of E-cadherin. The findings indicate that a reduction of Ecadherin and syndecan-1 expression occurs in a coordinated manner during tumor cell invasion.

\section{MATERIALS AND METHODS}

\section{Cell culture}

Normal murine mammary gland (NMuMG) cells (Owens et al., 1974) and their derivatives were cultured in Dulbecco's Modified Eagle's Medium (DMEM) supplemented with 10\% fetal calf serum (FBS) and $10 \mu \mathrm{g} / \mathrm{ml}$ insulin. Transfections of the E-cadherin cDNAs in sense and anti-sense orientations were performed by Vleminckx et al. (1991). NM-e-ras-G1 and NM-e-ras-MAC-1 cells are derived from NM-e cells that have been transfected with c-Ha-ras and then with either plasmid pMSG expressing Ecogpt only, or plasmid pMSG-MAC1 expressing Ecogpt and E-cadherin specific antisense RNA, respectively. NM-f-ras-TD-G1 and NM-f-ras-TD-CAM5 cells are derived from NM-f-ras-TD1 cells that have been cotransfected with plasmid pSV2gtp expressing Ecogpt and either high molecular weight DNA of NMuMG cells or plasmid pBATEM2 expressing mouse E-cadherin cDNA, respectively. The accumulation of newly synthesized syndecan-1 core protein in cells was induced by a pretreatment of 6 $\mu \mathrm{g} / \mathrm{ml}$ brefeldin A (BFA; Sigma) in culture medium for 6 hours.

\section{Immunofluorescence staining}

Cells were grown on glass coverlips to semiconfluence and then fixed with 3\% paraformaldehyde (PFA) or with ice-cold methanol. Prior to E-cadherin staining, PFA-fixed cells were permeabilized with $0.5 \%$ Triton X-100 in phosphate buffered saline (PBS, pH 7.4). Cells were washed and blocked with $1 \%$ bovine serum albumin (BSA) in PBS. Incubations with primary antibody were done at room temperature (RT) for 1 hour using syndecan-1-specific monoclonal antibody (mAb) 281-2 (30 $\mu \mathrm{g} / \mathrm{ml})$ (Jalkanen et al., 1985), E-cadherin-specific mAb DECMA-1 (1:200 dilution; Sigma), or R322 rabbit antiserum against $\beta 1$-integrin subunit (1:50 dilution) (Heino et al., 1989) in PBS supplemented with $1 \%$ BSA. After several washes bound antibodies were detected using FITC-conjugated anti-rat IgG (1:40 dilution) or FITC-conjugated anti-rabbit IgG (1:40 dilution) in PBS and 1\% BSA for 1 hour at RT. Cells were further washed extensively and mounted using Glysergel (Dako, Glostrup, Denmark).

\section{Flow cytometry}

Monolayer cells were washed with ice-cold PBS, detached with 0.5 mM EDTA, resuspended in PBS and centrifuged. Cells were then incubated with mAb 281-2 or mAb DECMA-1 in 1\% BSA-PBS at $4^{\circ} \mathrm{C}$ for 30 minutes, washed with PBS, and resuspended in $1 \%$ BSAPBS containing FITC-conjugated anti-rat IgG. After another 30 minute incubation at $4^{\circ} \mathrm{C}$, the cells were washed and fixed with $1 \%$ PFA in PBS. Analyses were done using quantitative FACStar ${ }^{\text {PLUS }}$ cytometer (Becton Dickinson, Mountain View, CA).

\section{Northern blotting}

Total RNA was isolated from semiconfluent cells by guanidine isothiocyanate extraction and cesium chloride gradient centrifugation as described (Chirgwin et al., 1979). RNA samples were fractionated by electrophoresis in a $1 \%$ agarose formaldehyde gel and transferred to Zeta probe membrane (Bio-Rad). The membrane was hybridized to the multi-prime labeled insert of PM-4 cDNA for mouse syndecan-1 (Saunders et al., 1989) and to rat glyceraldehyde 3-phosphate dehydrogenase cDNA (GAPDH) (Fort et al., 1985). pI-19 cDNA for mouse 28 S ribosomal RNA (Arnheim, 1979) was used as a reference probe. Quantitations were performed with image analyser system (Microcomputer Imaging Device version M4; Imaging Research Inc.).

\section{Quantitation of syndecan-1 on cell surfaces and in culture medium}

For quantitation of syndecan-1, cells were cultured for 3 days and fresh medium was added 24 hours prior to ectodomain isolation. To detect syndecan-1 shed from the cell surfaces, conditioned medium 
was collected. To detect syndecan-1 on cell surfaces, monolayers were washed once with cold PBS, detached by $0.5 \mathrm{mM}$ EDTA-PBS, and washed again. Cells were then suspended in EDTA-PBS and treated with $20 \mu \mathrm{g} / \mathrm{ml}$ of trypsin (Sigma) for 10 minutes on ice. After incubation $100 \mu \mathrm{g} / \mathrm{ml}$ of trypsin inhibitor (Sigma) and $1 \mathrm{mM}$ phenylmethylsulfonyl fluoride (PMSF; Sigma) were added and cells were centrifuged. Supernatant was recovered for ectodomain quantitation and cells were suspended in Isoton for cell counting with a Coulter Counter (Coulter Electronics, Harpenden, UK).

Supernatants from $1 \times 10^{5}$ cells and equal amounts of conditioned medium were loaded onto a cationic nylon membrane (Zeta-Probe, Bio-Rad) in a minifold-slot apparatus (Schleicher \& Schuell). Nonspecific binding was blocked with 5\% non fat dry milk in PBS for 30 minutes at RT. The membrane was then incubated overnight at $4{ }^{\circ} \mathrm{C}$ with radioiodinated $\mathrm{mAb} 281-2(10,000 \mathrm{cpm} / \mathrm{ml})$ in blocking buffer. After washes with PBS the bound antibody was visualized by autoradiography and quantitated by image analyser.

\section{Western blotting}

BFA-treated cells were washed with PBS, and syndecan-1 ectodomain was released by trypsin. Trypsin inhibitor was added to $500 \mu \mathrm{g} / \mathrm{ml}$ and PMSF to $1 \mathrm{mM}$. Cells were centrifuged, washed with PBS and lysed with $0.5 \%$ Triton-X-100 in immunoprecipitation buffer at $4^{\circ} \mathrm{C}$. For comparison of different samples, lysates containing equal amounts of proteins and corresponding trypsin-releasable materials were precipitated with 3 vols ethanol and fractionated by electrophoresis using a 7.5\% homogenous polyacrylamide gel (SDSPAGE) (Laemmli, 1970). After electrophoresis, samples were electroblotted onto Hybond- $\mathrm{N}^{+}$nylon membranes (Amersham). Membranes were blocked with $10 \%$ non fat dry milk and $0.4 \%$ Tween-20 in PBS and probed for syndecan- 1 overnight at $4^{\circ} \mathrm{C}$ with monoclonal antibody $281-2(2.5 \mu \mathrm{g} / \mathrm{ml})$ in PBS containing $0.4 \%$ Tween-20. Membranes were washed four times with PBS containing $0.4 \%$ Tween-20, and then further incubated with HRP-conjugated goat anti-rat IgG (1:5000) in 0.4\% Tween-20-PBS for 1 hour at RT. After washing as above, antigens were visualized using an enhanced chemiluminence kit (Amersham) and exposure at RT.

\section{Immunoprecipitations}

For immunoprecipitations cells were labeled from 6 hours to overnight with $50 \mu \mathrm{Ci} / \mathrm{ml}\left[{ }^{35} \mathrm{~S}\right]$-methionine (Trans ${ }^{35} \mathrm{~S}-l a b e l, \mathrm{ICN}$ ) in methionine-free DMEM supplemented with 5\% dialyzed FBS. Labeled cells were washed with immunoprecipitation buffer $(150 \mathrm{mM}$ $\mathrm{NaCl}, 1 \mathrm{mM} \mathrm{MgCl} 2,1 \mathrm{mM} \mathrm{CaCl}, 25 \mathrm{mM}$ Tris-HCl, $\mathrm{pH}$ 7.4) scraped or trypsinized from the culture dishes, washed and lysed in immunoprecipitation buffer containing $100 \mathrm{mM}$ octylglycoside. Detergent soluble fractions were preabsorbed by incubation with protein-ASepharose beads (Pharmacia, Sweden) for 2 hours and after removing the beads, the solution was mixed with mAb DECMA-1 for Ecadherin or with R322 antiserum for $\beta 1$-integrins, and incubated for 12 hours at $4^{\circ} \mathrm{C}$. Immunocomplexes were collected using rabbit antirat IgG (for mAb DECMA-1) and Protein-A-Sepharose beads for 2 hours at $4^{\circ} \mathrm{C}$, washed 4 times with immunoprecipitation buffer containing $0.1 \%$ BSA and $0.1 \%$ Triton-X-100 and twice with immunoprecipitation buffer, alone. The beads were collected by centrifugation, suspended in sample buffer and boiled. Samples were analyzed in a 6\% homogenous SDS-PAGE (Laemmli, 1970). After electrophoresis the gels were subjected to fluorography using the PPO enhancing system.

\section{RESULTS}

\section{Expression of E-cadherin in mammary epithelial tumor cells}

To investigate the coordinated regulation of cell-cell and cellmatrix interactions during malignant transformation we used eight murine mammary tumor variants that have been used to demonstrate invasion suppression activity of E-cadherin. The cells are derived from the NMuMG cell line, which is an uncloned heterogeneous cell population (Owens et al., 1974). Variants exhibit growth and phenotypic diversities due to subcloning and genetic manipulation with c-Ha-ras oncogene and E-cadherin cDNA, and can be divided into two subfamilies according to their epithelioid (NM-e) and fibroblastic (NM-f) stem cell clones (Table 1). The distribution of E-cadherin was examined by immunofluorescence microscopy using a mAb DECMA-1 (Fig. 1). As shown by Vleminckx et al. (1991), NM-e-derived cells were found to express E-cadherin, which was concentrated at their intercellular boundaries. These cells include NM-e cell clone (Fig. 1A), parental NM-e-ras (Fig. 1B), and control-transfected NM-e-ras-G1 cell lines (Fig. 1C). However, NM-e-ras-MAC-1 cells (Fig. 1D) expressing Ecadherin-specific antisense RNA showed a fibroblastic morphology and less intense E-cadherin staining as compared with other NM-e-derived cells.

Ras-transformed derivatives of NM-f cells were obtained by transfection of cells with genomic DNA from human tumor cell line T24. Such cells were injected subcutaneously into

Table 1. Expression of mutated p21 ${ }^{\text {ras }}$, E-cadherin and syndecan-1 in mammary epithelial cells with different invasive phenotypes

\begin{tabular}{|c|c|c|c|c|c|}
\hline \multirow[b]{2}{*}{ Cell line } & \multirow[b]{2}{*}{ Description } & \multicolumn{4}{|c|}{ Phenotype } \\
\hline & & Mutated p21 ras & E-cadherin & Syndecan-1 & Invasiveness \\
\hline NMuMG & Mouse mammary epithelial cell line & - & + & ++ & - \\
\hline NM-e & Subclone from NMuMG cells & - & + & ++ & - \\
\hline NM-e-ras & NM-e cells transfected with c-Ha-ras & + & + & ++ & - \\
\hline NM-e-ras-G1 & NM-e-ras cells transfected with control plasmid & + & + & ++ & - \\
\hline NM-e-ras-MAC1 & NM-e-ras cells expressing E-cadherin-specific anti-sense RNA & + & $+/-$ & $+/-$ & + \\
\hline NM-f & Subclone from NMuMG cells & - & $-1+$ & - & - \\
\hline NM-f-ras-TD1 & $\begin{array}{l}\text { NM-f cells transfected with DNA from T } 24 \text { cell line, } \\
\text { followed by s.c. injection into nu/nu mice }\end{array}$ & + & - & - & + \\
\hline NM-f-ras-TD-G1 & NM-f-ras-TD1 cells transfected with control plasmid & + & - & - & + \\
\hline NM-f-ras-TD-CAM5 & NM-f-ras-TD1 cells expressing E-cadherin cDNA & + & + & + & - \\
\hline
\end{tabular}

Cells were surface-stained for immunofluorescence. Intensity of stainings was scored as follows: -, negative; -/+, weak; +/-, partial downregulation; +, moderate; ++ , strong. Invasiveness was formerly determined in vitro with embryonic chick heart or collagen matrix as a target; scores are as follows; - , negative; + , positive (Vleminckx et al., 1991). 
Fig. 1. Immunostaining of Ecadherin in NM cells. Cells were fixed with $3.0 \%$ PFA and permeabilized with $0.5 \%$ Triton-X-100. E-Cadherin was localized at the intercellular boundaries of epithelial-like cells by using a monoclonal antibody DECMA-1. Cell lines: (A) NM-e; (B) NM-e-ras; (C) NM-e-ras-G1; (D) NM-e-rasMAC1; (E) NM-f; (F) NM-fras-TD1; G. NM-f-ras-TD-G1, H. NM-f-ras-TD-CAM5. Bar, $25 \mu \mathrm{m}$.
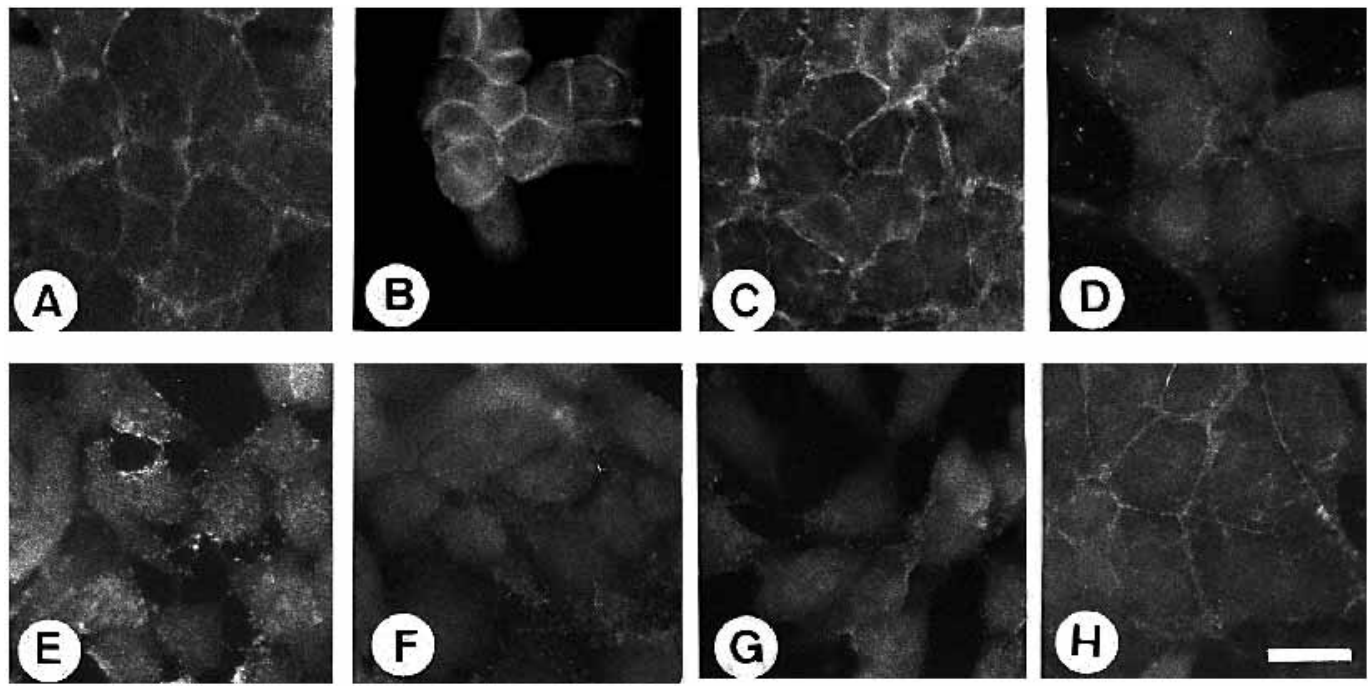

athymic nude mice. NM-f-ras-TD1 is the established cell line that was isolated from the resulting malignant tumors. From NM-f-derivative stem cells (Fig. 1E), parental NM-f-ras-TD1 (Fig. 1F), and control transfected NM-f-ras-TD-G1 cells (Fig. $1 \mathrm{G})$ expressed fibroblastic morphology and showed diffuse Ecadherin staining that was not detectable at the sites of cellcell contacts. On the contrary, in NM-f-ras-TD-CAM5 trans- fectants expressing exogenous E-cadherin (Fig. 1H), staining was localized mostly at the cell-cell contact areas.

\section{Expression of syndecan-1 in epithelial tumor cells is controlled by E-cadherin}

The localization of syndecan-1 on cell surfaces was then analyzed by using mAb 281-2 (Fig. 2). Similar to E-cadherin
Fig. 2. Immunostaining of syndecan-1 in NM cells. Cells were fixed with $3.0 \%$ PFA and syndecan-1 was localized on the cell surfaces of epithelial-like cells by using a monoclonal antibody 281-2. Cell lines: A. NM-e; B. NM-e-ras; C. NM-eras-G1; D. NM-e-ras-MAC1; E. NM-f; F. NM-f-ras-TD1; G. NM-f-ras-TD-G1, H. NM-f-ras-TD-CAM5; I. NM-e-ras, negative control; stained only with FITCconjugated anti-rat IgG. Bar, $25 \mu \mathrm{m}$.
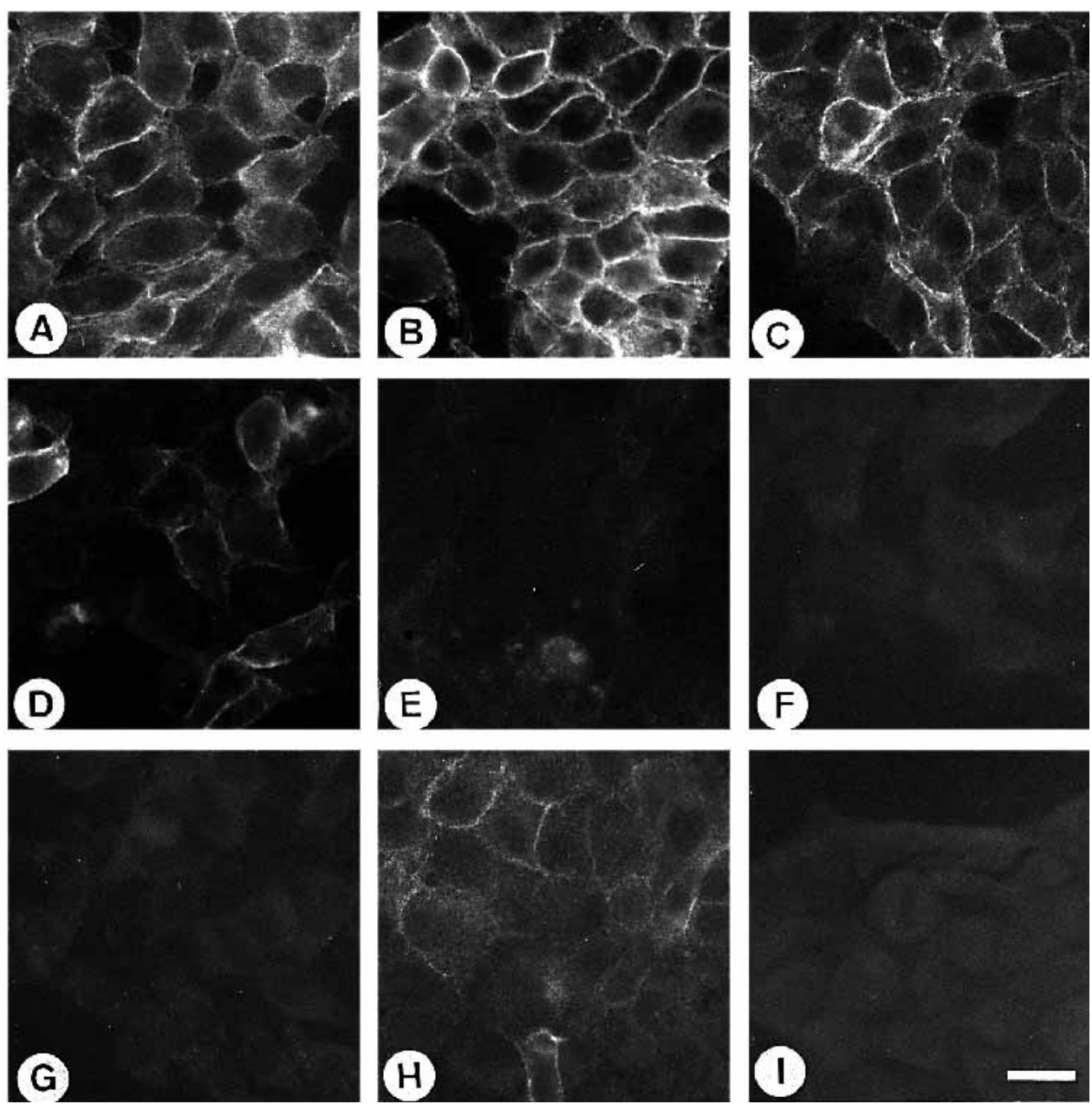
staining, syndecan-1 was strongly expressed in three epithelioid cell lines including NM-e cells (Fig. 2A), parental NM-e-ras (Fig. 2B) and control transfectant NM-e-ras-G1 (Fig. 2C). The staining was localized on the membranes particularly at the areas of cell-cell contacts. Instead, on NM-e-ras-MAC1 cells a clear downregulation of syndecan-1 expression was detected (Fig. 2D). All NM-f-derived cells (Fig. 2E-G) except E-cadherinexpressing transfectant NM-f-ras-TD-CAM5 (Fig. 2H) were negative for syndecan-1 staining. NM-f-ras-TD-CAM5 cells (Fig. $2 \mathrm{H}$ ) showed positive syndecan-1 expression at their cell surfaces that was not observed with control stainings (Fig. 2I).

The expression levels of E-cadherin and syndecan-1 were further compared using FACS analysis (Fig. 3). Both parental NM-e-ras and control transfected NM-e-ras-G1 cells expressed high amounts of syndecan-1 and E-cadherin at their cell surfaces. However, in NM-e-ras-MAC1 cells, which show a twofold reduction in E-cadherin expression, syndecan-1 was also suppressed (Fig. 3A). With regard to NM-f-derived cells, syndecan-1 expression was also positively correlated with Ecadherin (Fig. 3B). Syndecan-1 expression was unchanged or slightly reduced in control-transfected NM-f-ras-TD-G1 cells as compared to parental NM-f-ras-TD1 cells. Similarly, Ecadherin was detected at low levels. Instead, a majority of Ecadherin-transfected cells were shown to express high levels of syndecan-1 and intermediate levels of E-cadherin.

\section{Syndecan-1 mRNA levels do not follow E-cadherin expression}

To test whether the changes in syndecan-1 expression correlate with mRNA levels total RNAs were analyzed by northern blotting. Hybridization with a cDNA probe for syndecan-1 revealed a decrease in the amount of syndecan-1 mRNA in NM-f-derived cells as compared to NM-e-derived ones (Fig. 4 ), suggesting that the suppression of syndecan-1 mRNAs in NM-f cells occurs at the level of transcription. However, the analysis of the levels of syndecan-1 mRNAs in E-cadherin manipulated cell lines showed that there was in fact no correlation between the levels of syndecan-1 mRNAs and the levels of E-cadherin or syndecan-1 proteins detected by immunofluorescence and FACS analysis. NM-e-ras-MAC1 cells accumulated syndecan-1 mRNA as much as other NM-e derived cells. Furthermore, syndecan-1 mRNA was not upregulated in E-cadherin-expressing NM-f-ras-TD-CAM5 cells if compared to other NM-f-derived cells (Fig. 4A). Quantitation by scanning and blotting the results against $28 \mathrm{~S}$ ribosomal RNA confirmed that E-cadherin expression does not affect the accumulation of syndecan-1 mRNAs (Fig. 4B).

\section{Syndecan-1 suppression is not due to increased proteolytic cleavage of the ectodomain}

One possible mechanism for the regulation of syndecan-1 expression is the proteolytic cleavage of syndecan-1 from the cell surface into culture medium (Jalkanen et al., 1987). Therefore, we measured shedding of syndecan-1 into the culture medium. Conditioned media were collected from the same cells, which were further analyzed for their syndecan-1 quantity by an established slot blot assay (Jalkanen et al., 1987). The quantitation of syndecan-1 from the cell surfaces agreed well with the immunofluoresence stainings (Fig. 5A and B). All cell lines were found to express detectable levels of syndecan-1, but the expression levels were approximately 5 times lower in NM-f-derived than in NM-e-derived cells (data not shown). Analysis of syndecan-1 from culture medium also revealed that suppression of syndecan-1 in NM-e-ras-MAC1cells was not due to increased proteolytic cleavage of the ectodomain (Fig. 5C). On the contrary, upregulation of syndecan-1 in NM-f-ras-TD-CAM5 cells was not due to decreased shedding into the culture medium but rather followed the expression onto the cell surfaces (Fig. 5D). When the total syndecan- 1 expression was estimated by adding the relative amounts of the cell surface syndecan- 1 to the amounts shed into the culture medium, a clear down-regulation of syndecan-1 protein was observed in NM-e-ras-MAC1 cells (data not shown). On the contrary, total syndecan-1 amounts were markedly increased in NM-f-ras-TD-CAM5 as compared to parental and control transfected cells (data not shown).

A

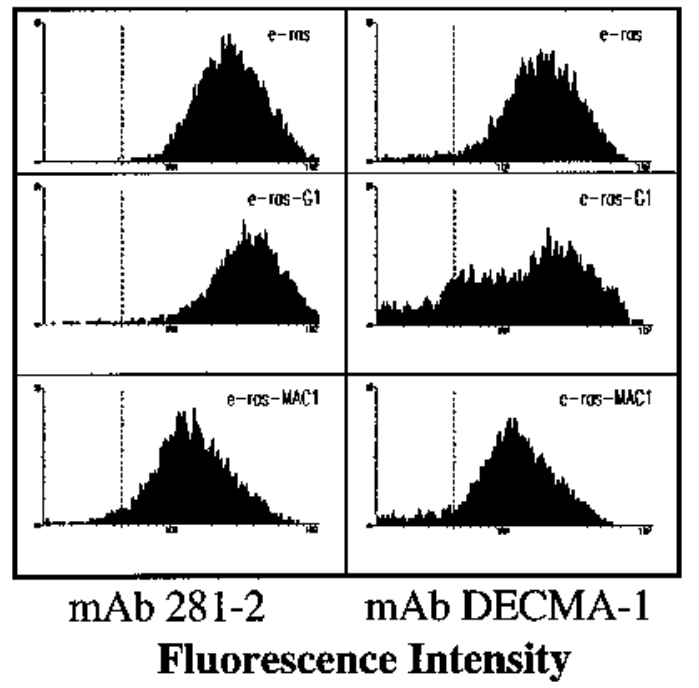

B

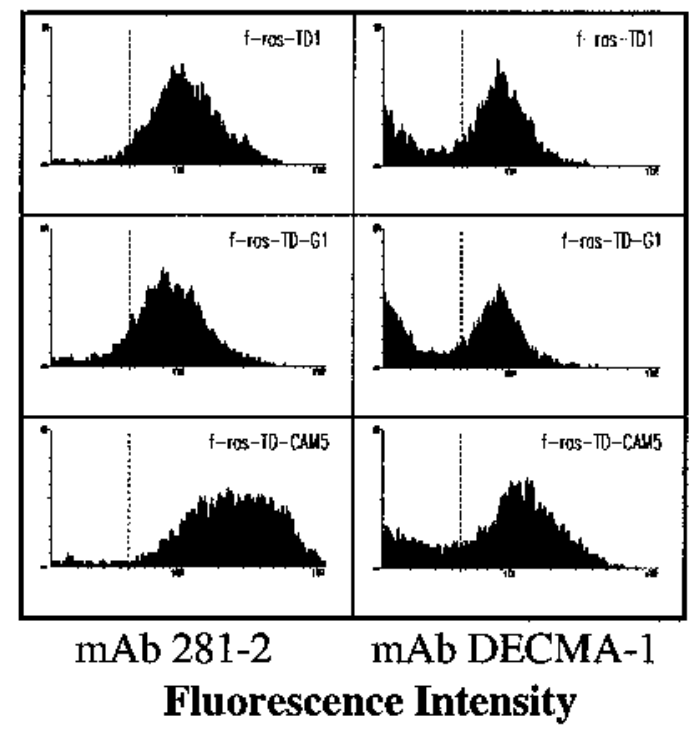

Fig. 3. FACS analysis of syndecan-1 and E-cadherin in NM-cells. Cells were stained in suspension with mAb 281-2 or mAb DECMA1 , fixed with $1 \%$ PFA and analyzed by FACS. 
A

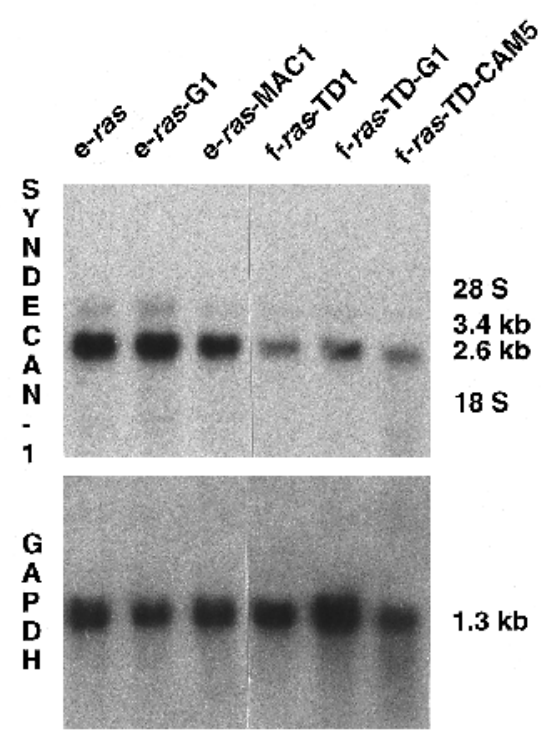

B

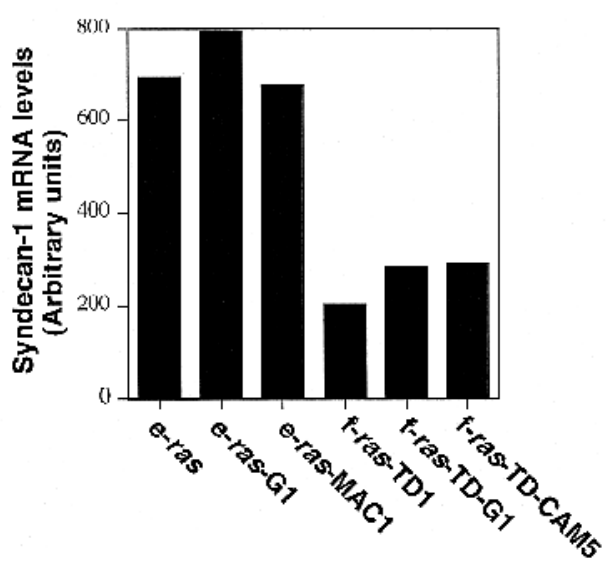

Fig. 4. (A) Northern analysis of syndecan-1 mRNA levels in NM cells. RNA samples of $10 \mu \mathrm{g}$ were fractioned on a $1 \%$ formaldehyde agarose gel, transferred onto Gene Screen Plus membrane, and hybridized to ${ }^{32} \mathrm{P}$-labeled probes for syndecan-1 and GAPDH. The migration of $18 \mathrm{~S}$ and $28 \mathrm{~S}$ ribosomal RNAs is indicated on the right. (B) Quantitation of syndecan-1 mRNA levels by image analyser. The values were normalized against $28 \mathrm{~S}$ ribosomal RNA.

\section{Syndecan-1 core protein synthesis is dependent on E-cadherin expression}

In many cells brefeldin A (BFA) results in a block in protein transport out of the endoplasmic reticulum to the Golgi and results in the retention of secretory and membrane proteins in the endoplasmic reticulum (Klausner et al., 1992). This allows the analysis of protein translation by visualization of newly synthesized core proteins in the endoplasmic reticulum. Recently it has also been shown that in a melanoma cell line BFA inhibits chondroitin sulfate chain elongation, but it does not affect protein synthesis (Spiro et al., 1991). Similarly, heparan sulfate chain elongation could be prevented by BFA in NMuMG-derived NOG-8 cells (Kirjavainen et al., 1993). Therefore, control transfected NM-e-ras-G1 cells and NM-eras-MAC1 cells expressing E-cadherin-specific antisense RNA were treated with $6 \mu \mathrm{g} / \mathrm{ml}$ BFA for 6 hours and then examined for the accumulation of syndecan-1 core protein. Cell surface material was isolated with trypsin and cells were further extracted with Triton X-100. Both fractions were analyzed by SDS-PAGE as shown in Fig. 6A. Syndecan-1 core protein, with an apparent size of $80 \mathrm{kDa}$, accumulated in control transfected NM-e-ras-G1 cells during BFA-treatment (Fig. 6A, lane 1). The typical smear of syndecan-1 was observed in the trypsin-released fraction of NM-e-ras-G1 cells (Fig. 6A, lane 2). Interestingly, syndecan-1 core protein from NM-e-ras-MAC1 cells accumulated notably less than that from control transfected cells (Fig. 6 A, lane 3). Similar suppression to that shown above (Fig. 3) was also detected in trypsin-released ectodomains from NM-e-ras-MAC-1 cells (Fig. 6A, lane 4). The obtained blot was further quantitated by image analyser, which showed a fivefold difference in the amount of syndecan-1 core protein between Nm-e-ras-G1 and NM-e-ras-MAC1 cells (Fig. 6C).

Equally to NM-e derived cell lines, control transfected NMf-ras-TD-G1 cells and NM-f-ras-TD-CAM5 cells expressing E-cadherin cDNA were treated with BFA (Fig. 6B). As expected from earlier analysis of syndecan-1 expression (Figs $2-5$ ), the levels of synthesized syndecan-1 core proteins were lower than those from NM-e-derived cells. Therefore, filters were subjected to a longer exposure. As shown in figure 6B, syndecan-1 core protein from control transfected NM-f-rasTD-G1 cells was hardly detectable (Fig. 6B, lane 1). The trypsin-released fraction of syndecan-1 appeared as a weak smear of approximately $250 \mathrm{kDa}$ (Fig. 6B, lane 2). However, syndecan-1 core protein from NM-f-ras-TD-CAM5 cells accumulated higher amounts than that from the control transfected cells (Fig. 6B, lane 3). Similar upregulation was noticed in the trypsin-released fraction of NM-f-ras-TD-CAM5 cells (Fig. 6B, lane 4). Quantitation showed that the increase in the
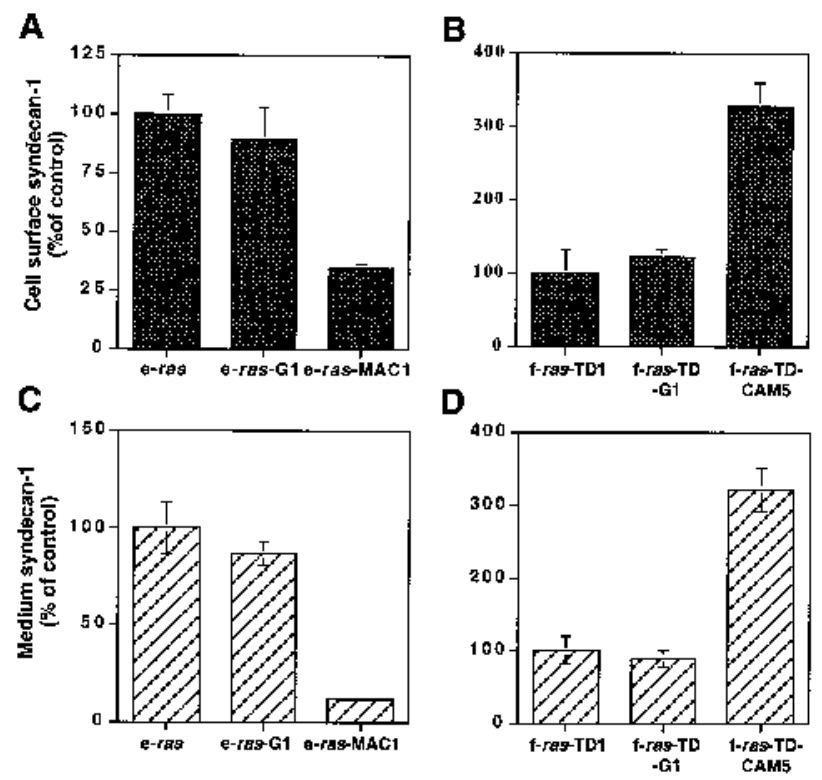

Fig. 5. Quantitation of syndecan-1 from NM-e-ras (A and C) and NM-f-ras TD1 (B and D) cells and their derivatives. Trypsinreleased ectodomains (A and $\mathrm{B}$ ) and conditioned medium (C and D) corresponding to $1 \times 10^{5}$ cells were loaded onto a cationic nylon membrane, and probed for syndecan- 1 with a radioiodinated $\mathrm{mAb}$ 281-2. Results are presented as \% of parental cell lines (mean \pm SD) from triplicate samples. 
A
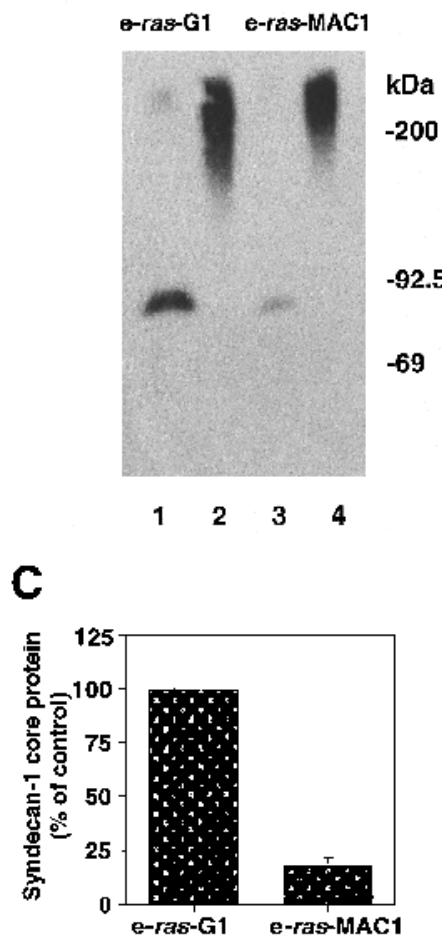

B

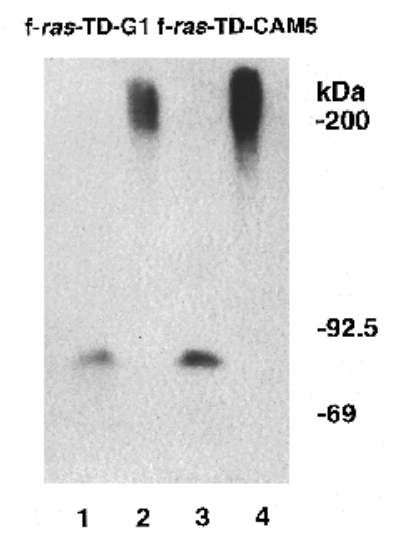

D

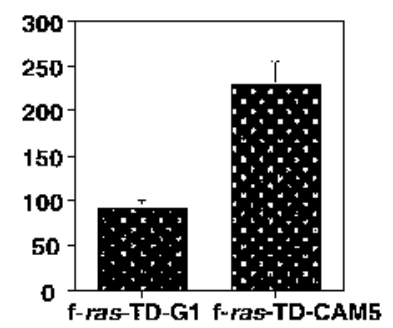

Fig. 6. Western blot of newly synthesized syndecan-1 in NM-e-rasand NM-f-ras-TD-derived cells. Cells were treated $6 \mathrm{~h}$ with BFA, detached with trypsin, and extracted with $0.5 \%$ Triton-X-100. For each cell line, intracellular (lanes 1 and 3 ) and cell surface (lanes 2 and 4) fractions were resolved in parallel in 7.5\% SDS-PAGE, and blotted onto Hybond- $\mathrm{N}^{+}$nylon membrane. Syndecan- 1 was detected with $\mathrm{mAb} 281-2$, followed by HRP-conjugated anti-rat IgG.

(A) Control transfected NM-e-ras-G1 cells (lanes 1 and 2) and NMe-ras-MAC1 cells expressing E-cadherin-specific anti-sense RNA (lanes 3 and 4). (B) Control-transfected NM-f-ras-TD-G1 cells (lanes 1 and 2) and NM-f-ras-TD-CAM5 cells expressing E-cadherin cDNA (lanes 3 and 4). Molecular weight markers are indicated on the right. (C and D) Quantitation of syndecan-1 core protein levels by image analyser. The results show the mean and range of two independent experiments.

amount of syndecan- 1 core protein was approximately 2.5 -fold in NM-f-ras-TD-CAM5 cells as compared to NM-f-ras-TDG1 cells (Fig. 6D).

The results were confirmed by immunostaining. Treatment of NM-cells with BFA resulted in a diffuse intracellular staining pattern, which resembled reticular staining typical for the endoplasmic reticulum but some syndecan-1 was still localized on the cell surface. A decreased accumulation of syndecan-1 in NM-e-ras-MAC1 cells and an increased accumulation of syndecan-1 in NM-f-ras-TD-CAM5 cells was also observed with this technique (data not shown). Immunoprecipitation analysis revealed that E-cadherin was also intracelluarly accumulated in BFA-treated cells with the exception of NM-f-ras-TD-G1 cells (Fig. 7A and B). E-cadherin was expressed mostly as a $135 \mathrm{kDa}$ precursor polypeptide but some $120 \mathrm{kDa}$ polypeptide form could also be detected.

To test the possibility that the suppression of syndecan-1 core protein reflects increased degradation in the endoplasmic reticulum we examined whether syndecan- 1 core protein was

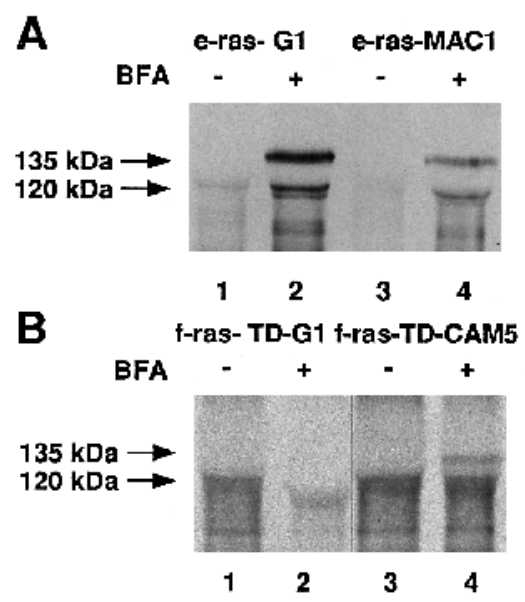

Fig. 7. Expression of E-cadherin in BFA-treated cells. Cells were incubated $6 \mathrm{~h}$ with BFA and $\left.{ }^{35} \mathrm{~S}\right]$ methionine, detached with trypsin and immunoprecipitated with mAb DECMA-1. Immunoprecipitated proteins were analyzed by $6 \%$ SDS-PAGE and fluorography.

degraded faster in cells expressing low levels of E-cadherin. Therefore, syndecan-1 core protein was accumulated for 3 hours and then chased for 1, 2 and 3 hours in the presence of BFA and cycloheximide. As a result we could not detect any clear differences in syndecan-1 core protein levels during the chase, and thus conclude that the core protein turnover rate is not markedly affected in E-cadherin-manipulated cells (data not shown).

\section{The expression of $\beta 1$-integrin subunit is not influenced by E-cadherin}

To address the specificity of the E-cadherin-dependent expression of syndecan-1, we examined the expression of another matrix binding protein, $\beta 1$ integrin, in E-cadherin manipulated NM cell lines. In the presence of divalent cations R322 antiserum can coprecipitate $\beta 1$-related $\alpha$-subunits (Heino et al., 1989). As shown in Fig. 8, the expression levels of $\beta 1$ integrin subunits and associated $\alpha$ s were similar in control transfected NM-e-ras-G1 (Fig. 8A, lane 1) and NM-e-rasMAC1 cells (Fig. 8A, lane 2) expressing E-cadherin-specific antisense RNA. Immunoprecipitation analysis revealed two major bands of similar size corresponding to $\alpha$ and $\beta 1$ subunits of integrin molecules, respectively. A $\beta 1$-precursor of approximately $115 \mathrm{kDa}$ was only faintly visible, suggesting that $\beta 1$ chain is processed relatively rapidly. The quantitation showed a $6 \%$ difference in the amount of $\beta 1$ subunit between Nm-eras-G1 and NM-e-ras-MAC1 cells. Similar expression levels and size of $\beta 1$-integrins were also observed in control transfected NM-f-ras-TD-G1 (Fig. 8A, lane 3) and E-cadherinexpressing NM-f-ras-TD-CAM5 cells (Fig. 8A, lane 4). The increase in the amount of $\beta 1$ subunit was $8 \%$ in NM-f-ras-TDCAM5 cells as compared to NM-f-ras-TD-G1 cells.

The $\beta 1$ integrin subunit was further localized by immunofluoresence. In both NM-e-ras-derived (Fig. 8B, panels A and B) and NM-f-ras-TD1-derived (Fig. 8B, panels C and D) transfectants $\beta 1$-integrin is transported to the cell surface but it does not show a clear concentrations at sites of cell-cell contacts. In permeabilized cells $\beta 1$-integrin shows a perinuclear staining pattern together with the distribution over the entire cell 
A

\section{e-ras- f-ras-TD- G1 MAC1 G1 CAM5}

Fig. 8. Expression of $\beta 1$-integrins in NM-e-ras- (lanes 1 and 2) and NM-f-ras-TD-derived cells (lanes 3 and 4). (A) Cells were metabolically labeled with $\left[{ }^{35} \mathrm{~S}\right]$ methionine, harvested and immunoprecipitated with R322 immunoserum specific for $\beta 1$ integrin subunit. Molecular weight markers are indicated on the right. (B) Immunolocalization of the $\beta 1$-integrin subunit in NMe-ras- and NM-f-ras-TD-derived cells. Cells were fixed with $3.0 \%$ PFA and stained for $\beta 1$-integrin subunit using R322

immunoserum. Cell lines: A. NMe-ras-G1; B. NM-e-ras-MAC1; C. NM-f-ras-TD-G1; D. NM-fras-TD-CAM5. Bar, $25 \mu \mathrm{m}$.

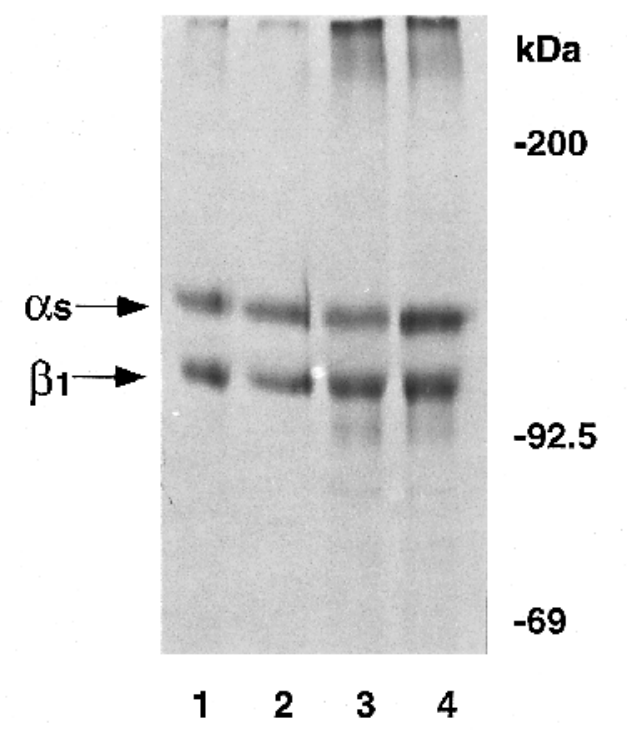

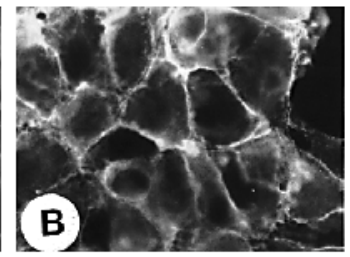
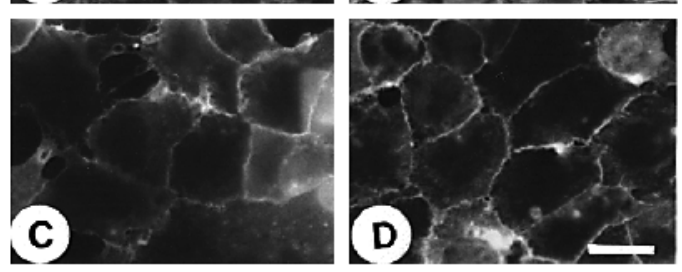

surface (data not shown). The perinuclear staining presumably represents $\beta 1$-integrins in endoplasmic reticulum and Golgi apparatus. In conclusion, these results show that $\beta 1$-integrin expression is not dependent on E-cadherin.

\section{DISCUSSION}

In the present study we have analyzed syndecan-1 expression in mouse mammary tumor cells genetically manipulated by Ecadherin-specific cDNA (Vleminckx et al., 1991). In this model E-cadherin expression correlates with the epithelioid phenotype and suppresses the invasive phenotype. Furthermore, downregulation of E-cadherin expression induces a fusiform phenotype and invasiveness of previously noninvasive epithelial cells. It is well established that the adhesive function of E-cadherin is mediated through the interaction of E-cadherin with catenins which in turn anchors the cadherincomplex to the actin filaments (Nagafuchi and Takeichi, 1989; Ozawa et al., 1989; McCrea et al., 1991; Reynolds et al., 1994; Shibamoto et al., 1995). Disruption of cell-cell contacts together with altered expression of other adhesive components would eventually lead to breakdown of the organized epithelial monolayer. We found that syndecan-1 expression was dependent on the expression of E-cadherin. Like E-cadherin, syndecan-1 is a molecule which has been shown to participate in the stabilization of epithelial cell sheets and cytoskeletal organization (Leppä et al., 1992; Mali et al., 1994; Kato et al., 1995). Our results show that E-cadherin and syndecan-1 are coordinately regulated and may thus act in concert to stabilize epithelial morphology.

Syndecan-1 from epithelial cells binds strongly to type I collagen in vitro (Koda et al., 1985). Recently, it was also shown that a direct interaction of syndecan-1 with type I collagen prevents B-lymphoid cell invasion (Liebersbach and Sanderson, 1994), indicating that syndecan-1 expression indeed can influence cell behavior by its extracellular interactions. In addition, syndecan-1 may also participate in cell-cell adhesion. Although it is localized on the entire surface of NMcells, it is strongly expressed at the intercellular spaces, which are not predominant expression sites for syndecan-1 ligands. Support for syndecan-1 participating in cell-cell adhesion can also be found from histological studies, where syndecan-1 was localized at lateral surfaces of simple epithelia and at the entire surface of stratified epithelia (Hayashi et al., 1987). Syndecan1 is also expressed at cell-cell contact areas in early mouse embryos (Sutherland et al., 1991), and in developing kidneys (Vainio et al., 1992).

\section{Coordinated expression of E-cadherin and syndecan-1}

Immunohistochemical studies have shown a similar expression pattern of E-cadherin and syndecan-1 in epithelial tumors. For example, they are both expressed in well-differentiated squamous cell carcinomas but are absent in poorly differentiated ones (Schipper et al., 1991; Inki et al., 1994b). E-cadherin and syndecan-1 are also expressed in well differentiated areas of epithelial tumors produced in nude mice (Inki et al., 1992b; Mareel et al., 1991a). Here, we have shown that both the localization and the expression levels of syndecan-1 mimic those of E-cadherin. The mechanisms that lead to suppression of syndecan-1 in NM-e-ras-MAC1 cells expressing E-cadherinspecific antisense RNA and conversely upregulation of syndecan-1 in E-cadherin expressing NM-f-ras-TD-CAM5 cells are unclear. It seems possible that E-cadherin and syndecan-1 may share same transport mechanisms, since BFA also blocked the transport of E-cadherin to the cell surface of NM-cells. On the other hand, in polarized MDCK cells the transport of both E-cadherin and syndecan-1, unlike the polyIg receptor, to the basolateral cell surface is not inhibited by BFA (Low et al., 1992; Apodaca et al., 1993, Miettinen et al., 1994). It is tempting to speculate that the excess of newly syn- 
thesized syndecan-1 in endoplasmic reticulum would rapidly be degraded unless E-cadherin is expressed at a certain threshold level. However, our results are against this hypothesis, since we could not detect any clear differences in the turnover of syndecan-1 core protein in the endoplasmic reticulum, whereas the accumulation of syndecan-1 core protein was affected (Fig. 6).

Another mechanism could be that E-cadherin expression is involved in the regulation of a large pattern of cellular proteins, which together maintain a particular phenotype inducing suppression of malignancy. Evidence for this comes from the study of McNeill and coworkers (1990), who showed that the expression of E-cadherin in transfected $\mathrm{L}$ fibroblasts lacking endogenous E-cadherin induces redistribution of the $\mathrm{Na}^{+}, \mathrm{K}^{+}$ ATPase to the sites of cell-cell-contacts. Therefore, E-cadherin would be a molecule involved in the polarization of epithelial cells. Syndecan-1 would function as a helper-molecule for Ecadherin, as it is capable of restoring the epithelial-like morphology in cancer cells (Leppä et al., 1992; Mali et al., 1994; Kato et al., 1995). It is also possible that a certain threshold level of syndecan-1 expression in some other cell types may have a signaling role for organization of a proper cytoskeletal network. This is supported by the finding that Schwann cells, which do not express syndecan-1, lack an organized actin filament network but aquire more prominent stress fibers after syndecan-1 transfection (Carey et al., 1994).

\section{A post-transcriptional mechanism regulates syndecan-1 expression in E-cadherin-manipulated cells}

Syndecan-1 mRNA levels were shown to be suppressed in all NM-f-derived cells, apparently independent of E-cadherin expression (Fig. 4). The difference in syndecan-1 mRNA levels between NM-e- and NM-f-derived cells possibly reflects alterations in the transcription rate or in mRNA stability. However, syndecan-1 core protein accumulation was shown to be Ecadherin-dependent (Fig. 6). BFA treatment allowed us to detect syndecan-1 core protein as a sharp band by western blotting, indicating that glycosylation of the core protein was prevented in these cells. Recently, it was shown that rat ovarian granulosa cells synthesize heparan sulfate proteoglycans in the presence of BFA (Uhlin-Hansen and Yanagishita, 1993). Together these studies indicate that depending on the cell type BFA can differentially affect the glysosaminoglycan elongation.

At the moment we can conclude that syndecan-1 core protein synthesis is affected by the expression of E-cadherin. A possible explanation for the reduced accumulation of syndecan-1 core protein in the presence of BFA is that translation of syndecan-1 is suppressed. In developing kidney, syndecan-1 expression appears to be post-transcriptionally regulated, since uninduced mesenchymal cells store syndecan1 mRNA and utilize it only after induction by the metanephric duct (Vainio et al., 1992). Similarly, syndecan-1 mRNA accumulates in peritoneal macrophages during inflammatory recruitment, but no syndecan-1 can be detected at protein level (Yeaman and Rapraeger, 1993). Furthermore, regulation may be translational also during malignant transformation; in spite of syndecan-1 mRNA accumulation in Ha-ras-transformed NOG-8 ras cells, newly synthesized core protein was barely detectable (Kirjavainen et al., 1993). Our results together with the previous findings suggest that post-transcriptional block may be a common process for controlling the expression of syndecan-1.

There are other examples of translational control in the regulation of protein expression. Stable secondary structures within the $5^{\prime}$-untranslated region ( $\left.5^{\prime} \mathrm{UTR}\right)$ have been suggested to inhibit the initiation of translation (Kozak, 1991). For example, ornithine decarboxylase mRNA, coding for the major regulatory enzyme in polyamine synthesis, and transforming growth factor- $\beta 1$ (TGF- $\beta 1$ ) mRNA contain a G/C-rich 5'UTR, that has been predicted to form stable stem-loop structures. These stem-loops were shown to inhibit translation of mRNAs (Manzella and Blackshear, 1990, Grens and Scheffler, 1990, Kim et al., 1992). Similarly, the 5'UTR of syndecan-1 mRNA has been predicted to form stable secondary structures (Saunders et al., 1989). The possibility that the 5'UTR of syndecan-1 mRNA exerts an inhibitory effect on syndecan-1 translation remains to be resolved.

While our study was in preparation, it was reported that suppression of syndecan-1 by antisense RNA results in downregulation of E-cadherin expression in mammary epithelial cells (Kato et al., 1995). The cells show a phenotype remarkably similar to that of cells expressing E-cadherin antisense RNA. Together these results suggest a coordinated expression of cell-cell and cell-substrate adhesion molecules during tumor cell invasion. Identification of the regulatory pathways used to coordinate the expression of genes participating in the constitution of the invasive phenotype in cancer will hopefully help us to understand this disease.

We thank Ms Taina Kalevo for excellent technical assistance. Drs Heini Miettinen, and Sue Edwards are thanked for scientific advice and discussions. This study was supported financially by the Academy of Finland, the Finnish Cancer Institute, the Finnish Cancer Union, the Farmos Research and Science Foundation and the Belgian National Fund for Scientific Research.

\section{REFERENCES}

Apodaca, G., Aroeti, B., Tang, K. and Mostov, K. E. (1993). Brefeldin-A inhibits the delivery of the polymeric immunoglobulin receptor to the basolateral surface of MDCK cells. J. Biol. Chem. 268, 20380-20385.

Arnheim, N. (1979). Characterization of mouse ribosomal gene fragments purified by molecular cloning. Gene 7, 83-96.

Becker, K. F., Atkinson, M. J., Reich, U., Becker, I., Nekarda, H., Siewert, J. R. and Höfler, H. (1994). E-cadherin gene mutations provide clues to diffuse type gastric carcinomas. Cancer Res. 54, 3845-3852.

Behrens, J., Mareel, M., Van Roy, F. and Birchmeier, W. (1989). Dissecting tumor cell invasion: Epithelial cells acquire invasive properties after the loss of uvomorulin-mediated cell-cell adhesion. J. Cell Biol. 108, 2435-2447.

Bernfield, M., Kokenyesi, R., Kato, M., Hinkes, M., Spring, J., Gallo, R. and Lose, E. (1992). Biology of the syndecans. Annu. Rev. Cell Biol. 8, 365393

Bosco, M., Chan, C., Matsuura, N., Takada, Y., Zetter, B. and Hemler, M. (1991). In vitro and in vivo consequences of VLA-2 expression in rhabdomyosarcoma cells. Science 251, 1600-1602.

Carey, D. J., Stahl, R. C., Cizmeci-Smith, G. and Asundi, V. K. (1994). Syndecan-1 expressed in Schwann cells causes morphological transformation and cytoskeletal reorganization and associates with actin during spreading. J. Cell Biol. 124, 161-170.

Chirgwin, J. M., Pryzbyla, A. E., McDonald, R. J. and Rutter, W. C. (1979). Isolation of biologically active ribonucleic acid from sources enriched in ribonuclease. Biochemistry 18, 5294-5299.

Elenius, K. and Jalkanen, M. (1994). Function of the syndecans - a family of cell surface proteoglycans. J. Cell Sci. 107, 2975-2982. 
Fort, P., Marty, L., Piechaczyk, M., El Sabroyty, S., Dani, C., Jeanteur, P. and Planchard, J. M. (1985). Various rat adult tissues express only one major mRNA species from glyceraldehyde-3-phosphate-dehydrogenase multigenic family. Nucl. Acids Res. 13, 1431-1442.

Frixen, U. H., Behrens, J., Sachs, M., Eberle, G., Voss, B., Warda, A., Löchner, D. and Birchmeier, W. (1991). E-Cadherin-mediated cell-cell adhesion prevents invasiveness of human carcinoma cells. J. Cell Biol. 113, 173-185.

Grens, A. and Scheffler, I. E. (1990). The 5'-and $3^{\prime}$-untranslated regions of ornithine decarboxylase mRNA affect the translational efficiency. J. Biol. Chem. 265, 11810-11816.

Hayashi, K., Hayashi, M., Jalkanen, M., Firestone, J. H., Trelstad, R. L. and Bernfield, M. (1987). Immunocytochemistry of cell surface heparan sulfate proteoglycan in mouse tissues. A light and electron microscopic study. J. Histochem. Cytochem. 35, 1079-1088.

Heino, J., Ignotz, R. A., Hemler, M. E., Crouse, C. and Massague, J. (1989). Regulation of cell adhesion receptors by transforming growth factor- $\beta$. $J$. Biol. Chem. 264, 380-388.

Hynes, R. O. (1992). Integrins: Versatility, modulation, and signalling in cell adhesion. Cell 69, 11-25.

Inki, P., Stenbäck, F., Talve, L. and Jalkanen, M. (1991). Immunohistochemical localization of syndecan in mouse skin tumors induced by UV irradiation. Am. J Pathol. 139, 1333-1340.

Inki, P., Gomez, M., Quintanilla, M., Cano, A. and Jalkanen, M. (1992a). Expression of syndecan in transformed mouse keratinocytes. Lab. Invest. 62, 225-233.

Inki, P., Kujari, H. and Jalkanen, M. (1992b). Syndecan in carcinomas produced from transformed epithelial cells in nude mice. Lab. Invest. 66 , 314-323.

Inki, P., Larjava, H., Haapasalmi, K., Miettinen, H. M., Grénman, R. and Jalkanen, M. (1994a). Expression of syndecan-1 is induced by differentiation and suppressed by malignant transformation of human keratinocytes. Eur. J. Cell Biol. 63, 43-51.

Inki, P., Joensuu, H., Grénman, R., Klemi, P. and Jalkanen, M. (1994b). Association between syndecan-1 expression and clinical outcome in squamous cell carcinoma of the head and neck. Br. J. Cancer 70, 319-323.

Inki, P., Stenbäck, F., Grénman, S., and Jalkanen, M. (1994c). Immunohistochemical localization of syndecan-1 in normal and pathological uterine cervix. J. Pathol. 172, 349-355.

Jalkanen, M., Nguyen, H., Rapraeger, A., Kurn, N. and Bernfield, M. (1985). Heparan sulfate proteoglycans from mouse mammary epithelial cells: Localization on the cell surface with a monoclonal antibody. J. Cell Biol. 101, 976-984.

Jalkanen, M., Rapraeger, A., Saunders, S. and Bernfield, M. (1987). Cell surface proteoglycan of mouse mammary epithelial cells is shed by cleavage of its matrix-binding ectodomain from its membrane-associated domain. $J$. Cell Biol. 105, 3087-3096.

Kato, M., Saunders, S., Nguyen, H. and Bernfield, M. (1995). Loss of cell surface syndecan- 1 causes epithelia to transform into anchorage-independent mesenchyme-like cells. Mol. Biol. Cell 6, 559-576.

Kawanishi, J., Kato, J., Sasaki, K., Fujii, S., Watanabe, N. and Niitsu, Y. (1995). Loss of E-cadherin-dependent cell-cell adhesion due to mutation of the $\beta$-catenin gene in a human cancer cell line, HSC-39. Mol. Cell. Biol. 15, 1175-1181.

Kim, S.-J., Park, K., Koeller, D., Kim, K. Y., Wakefield, L. M., Sporn, M. B. and Roberts, A. B. (1992). Post-transcriptional regulation of the human transforming growth factor- $\beta 1$ gene. J. Biol. Chem. 267, 13702-13707.

Kirjavainen, J., Leppä, S., Hynes, N. and Jalkanen, M. (1993). Translational suppression of syndecan-1 expression in Ha-ras transformed mouse mammary epithelial cells. Mol. Biol. Cell 4, 849-858.

Klausner, R. D., Donaldson, J. G. and Lippincott-Schwartz, J. (1992). Brefeldin A: insights into the control of membrane traffic and organelle structure. J. Cell Biol. 116, 1071-1080.

Koda, J. E., Rapraeger, A. and Bernfield, M. (1985). Heparan sulfate proteoglycans from mouse mammary epithelial cells. Cell surface proteoglycan as a receptor for interstitial collagens. J. Biol. Chem. 260, 81578162.

Kozak, M. (1991). An analysis of vertebrate mRNA sequences: Intimations of translational control. J. Cell Biol. 115, 887-903.

Laemmli, U. K. (1970). Cleavage of structural proteins during the assembly of the head of bacteriophage T4. Nature 227, 680-685.

Leppä, S., Härkönen, P. and Jalkanen, M. (1991). Steroid-induced epithelial-fibroblastic conversion associated with syndecan suppression in S115 mouse mammary tumor cells. Cell Regul. 2, 1-11.
Leppä, S., Mali, M., Miettinen, H. M. and Jalkanen, M. (1992). Syndecan expression regulates cell morphology and growth of mouse mammary epithelial tumor cells. Proc. Nat. Acad. Sci. USA 89, 932-936.

Liebersbach, B. F. and Sanderson, R. D. (1994). Expression of syndecan-1 inhibits cell invasion into type I collagen. J. Biol. Chem. 269, 20013-20019.

Liotta, L. A., Rao, C. N. and Wewer, U. M. (1986). Biochemical interactions of tumor cells with the basement membrane. Annu. Rev. Biochem. 55, 1037 1057.

Low, S. H., Tang, B. T., Wong, S. H. and Hong, W. (1992). Selective inhibition of protein targeting to the apical domain of MDCK cells by brefeldin A. J. Cell Biol. 118, 51-62.

Mali, M., Andtfolk, H., Miettinen, H. M. and Jalkanen, M. (1994). Suppression of tumor cell growth by syndecan-1 ectodomain. J. Biol. Chem. 269, 27795-27798.

Manzella, J. M. and Blackshear, P. J. (1990). Regulation of rat ornithine decarboxylase mRNA translation by its 5'-untranslated region. J. Biol. Chem. 265, 11817-11822.

Mareel, M. M., Behrens, J., Birchmeier, W., Bruyne, G. K., Vleminckx, K., Hoogewus, A., Fiers, W. C. and Van Roy, F. M. (1991a). Down-regulation of E-cadherin expression in Madin Darby canine kidney (MDCK) cells inside tumors of nude mice. Int. J. Cancer 47, 922-928.

Mareel, M. M., De Baetselier, P. and Van Roy, F. M. (1991b). Mechanisms of Invasion and Metastasis. Uniscience Books, CRC Press Inc., Boca Raton, Florida, USA.

Matsuyoshi, N., Hamaguchi, M., Taniquchi, S., Naqa Fuchi, A., Tsukita, S. and Takeicni, M. (1992). Cadherin mediated cell-cell adhesion is pertubated by v-src tyrosine phosphorylation in metastatic fibroblasts. J. Cell Biol. 118, 703-714.

McCrea, P., Turck, C. and Cumbiner, B. (1991). A homolog of the armadillo protein in Drosophila (plakoglobin) associated with E-cadherin. Science 254, 1359-1361

Miettinen, H. M. and Jalkanen, M. (1994). The cytoplasmic domain of syndecan-1 is not required for association with Triton X-100-insoluble material. J. Cell Sci. 107, 1571-1581.

Miettinen, H. M., Edwards, S. and Jalkanen, M. (1994). Analysis of transport and targeting of syndecan-1: Effect of cytoplasmic tail deletions. Mol. Biol. Cell 5, 1325-1339.

McNeill, H., Ozawa, M., Kemler, R. and Nelson, W. J. (1990). Novel function of the cell adhesion molecule uvomorulin as an inducer of cell surface polarity. Cell 62, 309-316.

Morton, R. A., Ewing, C. M., Nagafuchi, A., Tsukita, S. and Isaacs, W. B. (1993). Reduction of E-cadherin levels and deletion of the alpha-catenin gene in human prostate cancer cells. Cancer Res. 53, 3585-3590.

Nagafuchi, A. and Takeichi, M. (1988). Cell binding function of E-cadherin is regulated by the cytoplasmic domain. EMBO J. 7, 3679-3684.

Nagafuchi, A. and Takeichi, M. (1989). Transmembrane control of cadherin mediated cell adhesion: a $94 \mathrm{kDa}$ protein functionally associated with a specific region of the cytoplasmic domain of E-cadherin. Cell Regul. 1, 37 44.

Oda, T., Kanai, Y., Oyama, T., Yoshiura, K., Shimoyama, Y., Birchmeier, W., Sugimura, T. and Hirohashi, S. (1994). E-cadherin gene mutations in human gastric carcinoma cell lines. Proc. Nat. Acad. Sci. USA 91, 18581862

Oyama, T., Kanai, Y., Ochiai, A., Akimoto, S., Oda, T., Yanagihara, A., Nagafuchi, A., Tsukita, S., Shibamoto, S., Ito, F., et al. (1994). A truncated $\beta$-catenin disrupts the interaction between E-cadherin and $\alpha$-catenin: a cause of loss of intercellular adhesiveness in human gastric carcinoma cell lines. Cancer Res. 54, 6282-6287.

Ozawa, M., Baribault, H. and Kemler, R. (1989). The cytoplasmic domain of the cell adhesion molecule uvomorulin associates with three independent proteins structurally related in different species. EMBO J. 8, 1711-1717.

Owens, R. B., Smith, H. S. and Hackett, A. J. (1974). Epithelial cell cultures from normal glandular tissue of mice. J. Nat. Cancer. Inst. 53, 261-269.

Rapraeger, A., Jalkanen, M. and Bernfield, M. (1986). Cell surface proteoglycan associates with the cytoskeleton at the basolateral cell surface of mouse mammary epithelial cells. J. Cell Biol. 103, 2683-2696.

Reynolds, A. B., Daniel, J., McCrea, P., Wheelock, M. M., Wu, J. and Zhang, Z. (1994). Identification of a new catenin: the tyrosine kinase substrate p120 $0^{\text {cas }}$ associates with E-cadherin complexes. Mol. Cell. Biol. 14, 8333-8342.

Salmivirta, M., Elenius, K., Vainio, S., Hofer, U., Chiquet-Ehrismann, R., Thesleff, I. and Jalkanen, M. (1991). Syndecan from embryonic tooth mesenchyme binds tenascin. J. Biol. Chem. 266, 7733-7739.

Salmivirta, M., Heino, J. and Jalkanen, M. (1992a.). Basic fibroblast growth 
factor-syndecan complex at cell surface or immobilized to matrix promotes cell growth. J. Biol.Chem. 267, 17606-17610.

Salmivirta, M., Rauvala, H., Elenius, K. and Jalkanen, M. (1992b). Neurite growth-promoting protein (amphoterin p30) binds syndecan. Exp. Cell Res. 200, 444-451.

Salmivirta, M., Mali, M., Heino, J., Hermonen, J. and Jalkanen, M. (1994). A novel laminin-binding form of syndecan-1 (cell surface proteoglycan) produced by syndecan-1 cDNA-transfected NIH-3T3 cells. Exp. Cell Res. 215, 180-188.

Saunders, S. and Bernfield, M. (1988). Cell surface proteoglycan binds mouse mammary epithelial cells to fibronectin and behaves as a receptor for interstitial matrix. J. Cell Biol. 106, 423-430.

Saunders, S., Jalkanen, M., O'Farrell, S. and Bernfield, M. (1989). Molecular cloning of syndecan, an integral membrane proteoglycan. J. Cell Biol. 108, 1547-1556.

Schipper, J. H., Frixen, U. H., Behrens, J., Unger, A., Jahnke, K. and Birchmeier, W. (1991). E-Cadherin expression in squamous cell carcinomas of head and neck: Inverse correlation with tumor dedifferentiation and lymph node metastasis. Cancer Res. 51, 6328-6337.

Shibamoto, S., Hayakawa, M., Takeuchi, K., Hori, T., Miyazava, K., Kitamura, N., Johnson, K. R., Wheelock, M. J., Matsuyoshi, N., Takeichi, M. and Ito F. (1995). Association of p120, a tyrosine kinase substrate, with E-cadherin/catenin complexes. J. Cell Biol. 128, 949-957.

Shimoyama, Y., Nagafuchi, A., Fujita, S., Gotoh, M., Takeichi, M., Tsukita, S. and Hirohashi, S. (1992). Cadherin dysfunction in a human cancer cell line: Possible involvement of loss of $\alpha$-catenin expression in reduced cell-cell adhesiveness. Cancer Res. 52, 5770-5774.

Sneed, T. B., Stanley, D. J., Young, L. A. and Sanderson, R. D. (1994). Interleukin-6 regulates expression of syndecan-1 proteoglycan on B lymphoid cells. Cell. Immunol. 153, 456-467.

Spiro, R. C., Freeze, H. H., Sampath, D. and Garcia, J. A. (1991).
Uncoupling of chondroitin sulfate glycosaminoglycan synthesis by brefeldin A. J. Cell Biol. 115, 1463-1473.

Sun, X., Mosher, D. and Rapraeger, A. (1989). Heparan sulfate-mediated binding of epithelial cell surface proteoglycan to thrombospondin. J. Biol. Chem. 264, 2885-2889.

Sutherland, A. E., Sandersson, R. D., Mayes, M., Seibert, M., Calarco, P. G., Bernfield, M. and Damsky, H. C. (1991). Expression of syndecan, a putative low affinity fibroblast growth factor receptor, in the early mouse embryo. Development 113, 339-351.

Takeichi, M. (1990). Cadherins: a molecular family important in selective cellcell adhesion. Annu. Rev. Biochem. 59, 237-252.

Takeichi, M. (1991). Cadherin cell adhesion receptors as a morphogenetic regulator. Science 251, 1451-1455.

Takeichi, M. (1993), Cadherins in cancer: implications for invasion and metastasis. Curr. Opin. Cell Biol. 5, 806-811.

Uhlin-Hansen, L. and Yanagishita, M. (1993). Differential effect of brefeldin A on the biosynthesis of heparan sulfate and chondroitin/dermatan sulfate proteoglycans in rat ovarian granulosa cells in culture. J. Biol. Chem. 268, 17370-17376.

Vainio, S., Jalkanen M., Bernfield, M. and Saxen, L. (1992). Transient expression of syndecan in mesenchymal cell aggregates of the embryonic kidney. Dev. Biol. 152, 221-232.

Vleminckx, K., Vakaet, L. Jr, Mareel, M., Fiers, W. and Van Roy, F. (1991). Genetic manipulation of E-cadherin expression by epithelial tumor cells reveals an invasion suppressor role. Cell 66, 107-119.

Yeaman, C. and Rapraeger, A. (1993). Post-transcriptional regulation of syndecan-1 expression by cAMP in peritoneal macrophages. J. Cell Biol. 122, 941-950.

(Received 11 December 1995 - Accepted 6 March 1996) 